\title{
The impact of the fourth industrial revolution: a cross-country/region comparison
}

\author{
Yongxin Liao ${ }^{\mathrm{a} *}$, Eduardo Rocha Loures ${ }^{\mathrm{a}}$, Fernando Deschamps ${ }^{\mathrm{a}}$, Guilherme Brezinski ${ }^{\mathrm{a}}$, \\ André Venâncio ${ }^{a}$ \\ aPontifícia Universidade Católica do Paraná, Curitiba, PR, Brazil \\ *yongxin.liao@pucpr.br
}

\begin{abstract}
The fourth industrial revolution stimulates the advances of science and technology, in which the lnternet of Things (loT) and its supporting technologies serve as backbones for Cyber-Physical Systems (CPS) and smart machines are used as the promoters to optimize production chains. Such advancement goes beyond the organizational and territorial boundaries, comprising agility, intelligence, and networking. This scenario triggers governmental efforts that aim at defining guidelines and standards. The speed and complexity of the transition to the new digitalization era in a globalized environment, however, does not yet allow a common and coordinated understanding of the impacts of the actions undertaken in different countries and regions. The aim of this paper, therefore, is to bridge this gap through a systematic literature review that identifies the most influential public policies and evaluates their existing differences. This cross-country/region comparison provides a worldwide panorama of public policies' durations, main objectives, available funding, areas for action, focused manufacturing sectors, and prioritized technologies. Findings of this review can be used as the basis to analyse the position of a country against the existing challenges imposed towards its own industrial infrastructure and also to coordinate its public policies.
\end{abstract}

Keywords

The fourth industrial revolution. Cross-country/region comparison. Systematic literature review. Qualitative analysis. Quantitative analysis.

How to cite this article: Liao, Y., Loures, E. R., Deschamps, F., Brezinski, G., \& Venâncio, A. (2017). The impact of the fourth industrial revolution: a cross-country/region comparison. Production, 28, e20180061. DO1: 10.1590/0103-6513.20180061

Received: July 31, 2017; Accepted: Nov. 22, 2017.

\section{Introduction}

According to the Cambridge Dictionary (2017), the term industrial revolution is initially defined as: "[...] the period of time during which work began to be done more by machines in factories than by hand at home". The advances in science and technology have continuously supported the development of industrialization all around the world, and have helped to bring more specific and explicit meanings to this term over the years (Belvedere et al., 2013).

Nowadays, even though there is still no universal agreement on what constitutes an industrial revolution (Maynard, 2015), four general phases have been identified from the perspective of the technological evolution (National Academy of Science and Engineering, 2013). The first industrial revolution is considered as one of the important advancements in humanity, which started by using water and steam-powered mechanical manufacturing facilities since the end of 18th century. Later, at the start of 20th century, the application of electrically-powered mass production technologies, through the division of labour, was marked as the second industrial revolution. After that, to support further automation of manufacturing, the third industrial revolution began, around mid-1970s, by popularizing electronics and information technology (IT) in factories. In total, these three industrial revolutions took roughly two centuries to develop. In the past few years, along with the increased research attention on the Internet of Things (loT) (Atzori et al., 2010) and Cyber-Physical Systems 
(CPS) (Khaitan \& McCalley, 2015), industry, governments and society in general have noticed the trend towards the "Fourth Industrial Revolution" and acted to benefit from what it could provide (Siemieniuch et al., 2015). Moreover, according to a previous work (Liao et al., 2017), the number of conferences and academic papers related to "Industrie 4.0" (one significant research effort within the fourth industrial revolution era) have gradually increased, from 2013 to 2015 , by 12.6 times and 24.2 times respectively.

Looking at the growing interest in the fourth industrial revolution all around the world, a question arises: what impact does the fourth industrial revolution bring to different countries and regions? This paper tries to answer this question by analysing academic contributions, based on systematic literature review methods presented by Nightingale (2009) and Pickering \& Byrne (2014). More specifically, two research sub-questions are listed as follows:

- Q1. What are the most influential public policies related to the fourth industrial revolution?

- Q2. What are the similarities and differences between these public policies?

The remaining sections of this paper are organized as follows: Section 2 presents the applied systematic literature review method and illustrates the data of interest. Based on these data, Section 3 characterizes the impact of the fourth industrial revolution through the qualitative and quantitative analysis of collected data related to each research sub-question. After that, a discussion of those findings is given in Section 4. Finally, Section 5 concludes this paper and points out future works.

\section{Systematic literature review methods}

Based on the Preferred Reporting ltems for Systematic review and Meta-Analysis (PRISMA) flow chart (Moher et al., 2009), Figure 1 presents the different stages of the systematic literature review undertaken in this work.

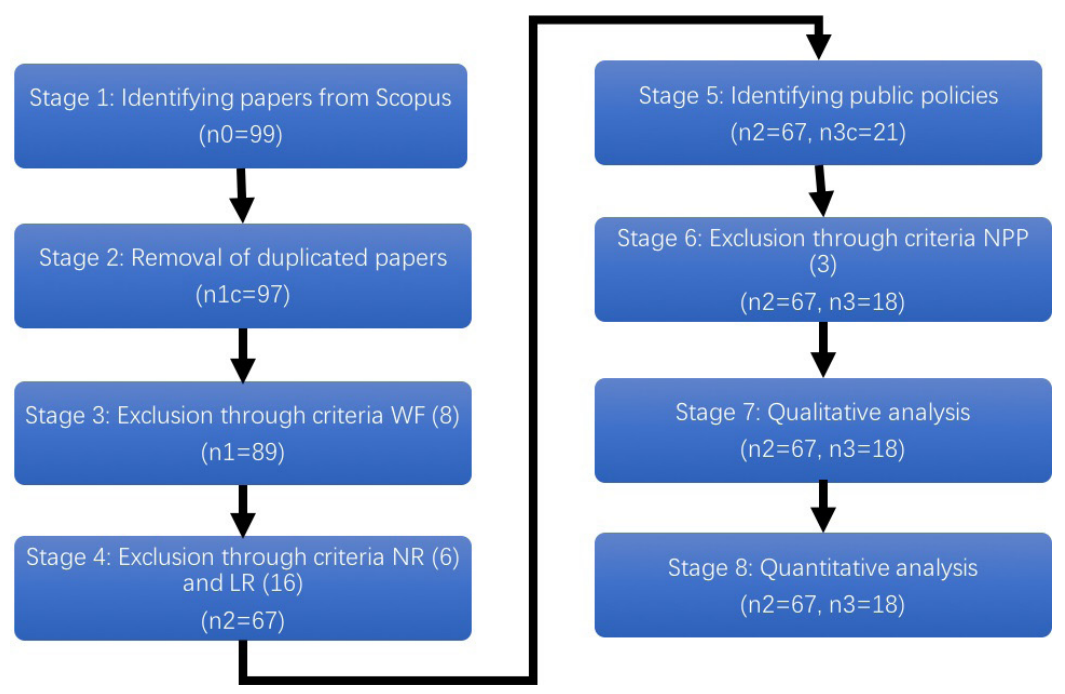

Figure 1. Systematic literature review stages adopted in this work.

In general, the first round of review (Stages 1, 2 and 3) takes the 99 papers retrieved from Scopus ( $n O$ in Figure 1) as its input, removes 2 duplicated papers in Stage 2, excludes 8 papers without full-text in Stage 3, and results in 89 papers ( $n 1$ in Figure 1). Then, these papers enter the second round of review (Stages 4 and 5), in which, 6 non-related papers and 16 loosely related papers are excluded (Stage 4). In Stage 5, through careful examination of the 67 included papers ( $n 2$ in Figure 1), 21 plans that were referenced by these papers were identified as candidates for the comparison ( $n 3 c$ in Figure 1). Finally, in the third round of review (Stage 6), 3 industrial plans were excluded and 18 official public policies ( $n 3$ in Figure 1) were included and studied in detail in Stages 7 and 8. More details on the procedures for each stage are given in the following subsections. 


\subsection{Paper collection method}

To collect a comprehensive set of academic contributions related to the fourth industrial revolution (Stage 1), the largest abstract and citation database of peer-reviewed literature, namely Scopus, was chosen, because it provides a comprehensive overview of the world's research output. A search string was constructed through the combination of the operator $O R$ in between two terms: "the fourth industrial revolution" and "the 4th industrial revolution". References that met the following criteria were collected:

- They were published online before the middle of March 2017;

- They contained one of the search terms in the abstract, title and/or keywords;

- They were written in the English language;

- They were published in conference proceedings, journals, book series, and books.

\subsection{Inclusion and exclusion policy}

To provide a more objective assessment of collected papers, six inclusion and exclusion criteria were defined, as can be seen in Table 1. After the duplicates were removed (Stage 2 in Figure 1), for each collected paper, the paragraphs that contain the search terms, from the search string described in Section 2.1, were briefly examined. Besides those without full-texts to be accessed (criteria $W F$ in Table 1, Stage 3 in Figure 1), the first round of review is conducted. The second round of review (Stage 4 in Figure 1) started by excluding the papers that defined the fourth industrial revolution out of the scope of this work ( $N R$ in Table 1$)$. After that, full-texts were examined to exclude those papers without mentioning any public policies and industrial projects ( $L R$ in Table 1), to collect papers with data of interest for the research sub-question Q1 ( $P R$ in Table 1), and to identify candidate public policies (Stage 5). During the third round of review (Stage 6), for each discovered plan, non-public policies (NPP in Table 1) were excluded and the official document of each public policy that contains its detailed descriptions ( $C R$ in Table 1 ) was collected. Finally, Stages 7 and 8 reviewed those collected public policy documents and collected corresponding data of interest for the research sub-question Q2.

Table 1. Inclusion and exclusion criteria and their explanations.

\begin{tabular}{|c|c|c|}
\hline $1 / \mathrm{E}$ & Criteria & Criteria Explanations \\
\hline \multirow[t]{4}{*}{ Exclusion } & Without Full-text (WF) & The authors have no access to its full text. \\
\hline & Non-Related (NR) & 1ts definition about "the fourth industrial revolution" is neither related to loT nor CPS. \\
\hline & Loosely-Related (LR) & $\begin{array}{l}\text { It does not contain any description related to a public policy or an industrial project. The search term } \\
\text { is only used as loose expression cited in the text without being the main focus. }\end{array}$ \\
\hline & Non-public policies (NPP) & It was proposed and carried out only by industries or just the name of an agency or a cluster. \\
\hline \multirow[t]{2}{*}{ Inclusion } & Partially- Related (PR) & It lists one or more public policies but without detailed description. \\
\hline & Closely Related (CR) & $\begin{array}{l}\text { An official document that contains the detailed descriptions of public policies within the fourth } \\
\text { industrial revolution era. }\end{array}$ \\
\hline
\end{tabular}

\subsection{Data collection method}

Data collection was performed in Stages 7 and 8 of Figure 1. For Q1, "What are the most influential public policies related to the fourth industrial revolution?", the data of interest are (1) the name of the public policies and industrial projects, and (2) their official reports or announcements (either physical or digital). For Q2 “What are the similarities and differences between these public policies?", the data of interest are (1) the start year and end year of each plan identified in Q1, (2) their main objectives or value propositions, (3) their available funding, (4) their main areas for action, (5) the manufacturing sectors they focus on, and (6) their prioritized technologies. Results of the analysis are presented in the next section. 


\section{Characterization of the cross-country/region impact}

\subsection{Public policies for Q1}

The analysis of existing public policies related to the fourth industrial revolution can provide an overall view of the effects on different countries and regions. Initially, from all included papers, only eleven countries and one region were mentioned, in which, just eight public policies were identified. They are listed as follows:

- “Industrie 4.0" from Germany (National Academy of Science and Engineering, 2013);

- "Made in China 2025" from China (2015);

- "Factories of the future" from Europe (European Factories of the Future Research Association, 2013);

- "Advanced Manufacturing Partnership" from the United States (President's Council of Advisors on Science and Technology, 2011, 2014);

- "Smart Industry" from the Netherlands (Netherlands, 2014);

- "Industria Conectada 4.0" from Spain (Spain, 2014b);

- "Eleventh Malaysia Plan" from Malaysia (Economic Planning Unit, 2015);

- “La Nouvelle France Industrielle” from France (Conseil National de L’industrie, 2013).

As can be seen from Figure 2, on the one hand, one can find that all included papers have mentioned the German plan "Industrie 4.0". Even more, some of them directly used this plan to represent the overall idea of "The Fourth Industrial Revolution". On the other hand, compared to the German plan, the plans from the other six countries and one region seem to be less popular in this new revolution wave, having only been mentioned in either one, two or three of the included papers.

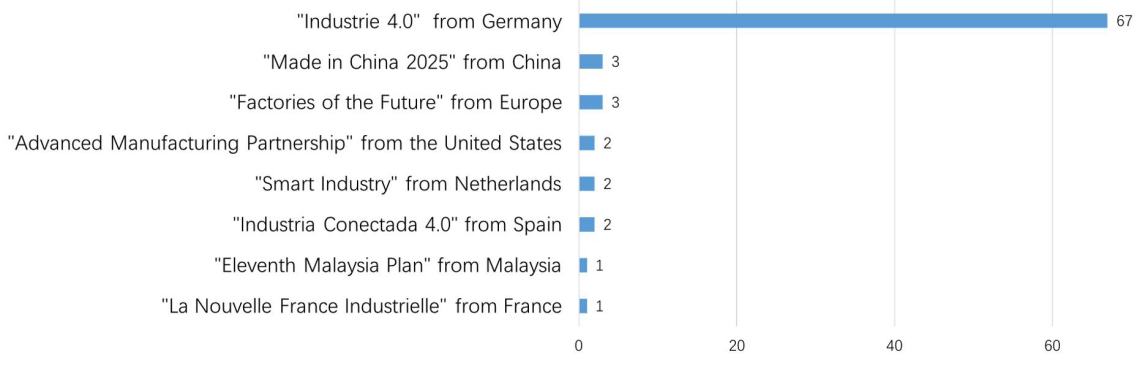

Figure 2. Number of included papers by public policies.

For the other three countries, no public policy could be directly identified from the collected papers (the United Kingdom, Sweden and ltaly), because the name of an industrial project, agency or cluster was used to represent their public policies. An extra effort was made to collect the public policies that related to the mentioned countries in the citing papers:

- "Future of Manufacturing" from the United Kingdom (Foresight, 2013);

- "Smart Industry" from Sweden (2016);

- "Piano Nazionale Industria 4.0" from Italy (2016).

Moreover, based on the 2016 Global Manufacturing Countries and Regions Competitiveness Index Report by the consulting group Deloitte Touche Tohmatsu (Deloitte, 2016), besides China, the United States, Germany, and the United Kingdom, the other six countries for which plans were retrieved were only ranked from 13 to 30 (see bold words in Table 2). To increase the reliability of this analysis and improve the completeness of the comparison in this work, the search for public policies was also extended to the top 10 manufacturing countries and regions in both the current year (2016) and the projected year (2020) according to Deloitte's report. Seven more plans were found: 
Table 2. Top manufacturing countries and regions, ranked according to Deloitte (2016).

\begin{tabular}{ccc}
\hline Country/Region & Rank 2016 (Current) & Rank 2020 (Projected) \\
\hline China & 1 & 2 \\
United States & 2 & 1 \\
Germany & 3 & 3 \\
Japan & 4 & 4 \\
South Korea & 5 & 6 \\
United Kingdom & 6 & 8 \\
Taiwan & 7 & 9 \\
Mexico & 8 & 7 \\
Canada & 9 & 10 \\
Singapore & 10 & 11 \\
India & 11 & 5 \\
Sweden & 13 & 18 \\
Malaysia & 17 & 13 \\
Netherlands & 20 & 21 \\
France & 22 & 26 \\
Spain & 25 & 27 \\
Italy & 28 & 30 \\
\hline
\end{tabular}

- "Super Smart Society" from Japan (Council for Science Technology and Innovation, 2015);

- "Manufacturing Innovation 3.0" from South Korea (2014);

- “Taiwan Productivity 4.0 Initiative” from Taiwan, a province of China (Executive Yuan, 2015);

- "Crafting the Future" from Mexico (2016);

- “Industrie 2030" from Canada (Canadian Manufacturers \& Exporters, 2016);

- "Research, Innovation and Enterprise 2020 Plan" from Singapore (National Research Foundation, 2016);

- "Make in India" from India (Department of Industrial Policy and Promotion, 2014).

In total, 18 government plans from different countries and regions were identified as the answer to research sub-question Q1. These plans will also serve as the basis for data collection and analysis for research sub-question Q2 in Section 3.2.

\subsection{The comparison of similarities and differences for Q2}

This section starts with a summary of each collected government plan for the disambiguation of terms (Section 3.2.1). Then, Section 3.2.2 divides the comparison of the plans into six parts: (1) duration, (2) main objectives, (3) available funding, (4) areas for action, (5) focused manufacturing sectors, and (6) prioritized technologies.

\subsubsection{Overview of public policies from different countries and regions}

\subsubsection{The fourth industrial revolution in North America}

In the United States, since June 2011, a series of national-level efforts related to what was called "Advanced Manufacturing Partnership (AMP)" was recommended by the President's Council of Advisors on Science and Technology (PCAST). It intends to bring together federal government, industries and universities to: (1) create a fertile environment for innovation, and (2) invest in new technologies and design methodologies (President's Council of Advisors on Science and Technology, 2011). Then, in September 2013, to succeed AMP, AMP 2.0 was launched and identified a number of further steps to: (1) enable innovation, (2) secure the talent pipeline, and (3) improve the business climate (President's Council of Advisors on Science and Technology, 2014).

In Mexico, its cost competitiveness advantage (i.e., low-cost labour force and high-volume production) has made it become a world-class manufacturing hub. Around half of its exports are manufactured products, of which a large portion are of highly sophisticated technologies (Mexico, 2016). To search for opportunities, 
develop capabilities beyond low cost, and also provide a long-term vision of the future of its manufacturing, a roadmap, named "Crafting the Future", was developed by Mexico's Ministry of Economy in April 2016.

In Canada, with the objective of doubling the value added by manufacturing, processing, technology and service industries by 2030, the "Industrie 2030" initiative was proposed by the Canadian Manufacturers \& Exporters (CME) association and publicly launched together with the Canadian Ministry of Innovation, Science and Economic Development in February 2016 (Canadian Manufacturers \& Exporters, 2016). In October 2016, the first phase of the "Industrie 2030" strategy plan was concluded through the release of a series of reports in Canada's National Manufacturing Summit.

\subsubsection{The fourth industrial revolution in Europe}

In Germany, the term "Industrie 4.0" first appeared at the Hannover Messe in April 2011 (Drath \& Horch, 2014). Since then, it began to attract more and more attention after it officially became one of the ten projects within the "High-Tech Strategy 2020" action plan in March 2012 (Liao et al., 2017). It aims to develop cutting-edge technologies for securing the future of German the manufacturing industry. The final report of the "Industrie 4.0" Working Group (National Academy of Science and Engineering, 2013) was published in April 2013, providing the vision, integration features, priority areas for action and example applications for the fourth industrial revolution.

In France, the first phase of "La Nouvelle France Industrielle", a strategic review, was launched by the France President in September 2013, defining 34 sector-based initiatives as France's industrial policy priorities (Conseil National de L'industrie, 2013). Then, in the middle of 2015, the second phase of this program was carried out through: (1) supplementing it with the Alliance for the Industry of the Future, which focuses on the modernization of France's production tools, and (2) presenting nine industrial solutions, which provide real-world responses to key economic and social challenges (Nouvelle France Industrielle, 2016).

In the United Kingdom (UK), since December 2011, a 2-year project was proposed to provide a long term and strategic picture about its manufacturing sector until 2050, namely the "Future of Manufacturing". As its result, in October 2013, the final project report was published by the Foresight Programme of the Government Office for Science (Foresight, 2013). Then, in April of 2016, a National Innovation Plan (NIP) was started by the Department for Business, Energy and Industrial Strategy to support and drive innovation. As a key part of this NIP, the new Delivery Plan of the "Innovate UK" agency has allocated nearly a quarter of its annually expenditure to projects related to Manufacturing and Materials (Innovate UK, 2016).

In Sweden, a strategic research and innovation agenda for innovation in production, named "Made in Sweden 2030" was proposed in April 2013, by Teknikföretagen (the Association of Swedish Engineering Industries), identifying six key areas to strengthen production and five instruments to secure long-term, efficient implementation of research and innovation (Teknikföretagen, 2013). Then, in June 2016, the "Smart Industry" strategy for new industrialization was announced by the Swedish Ministry of Enterprise and Innovation to strengthen companies' capabilities for change and to compete. Industry 4.0 is listed as one of its four focus areas (Sweden, 2016).

In Spain, the "Industria Conectada 4.0" has been launched in July 2015 by the Spanish Ministry of Industry, Energy and Tourism (MINETUR), with the aim of promoting the digital transformation of Spanish industry through the joint and coordinated action of the public and private sectors (Spain, 2014b). This initiative is (1) complementary to the "Agenda for the Strengthening of the Industrial Sector in Spain", approved by the Council of Ministers in July 2014 (Spain, 2014a), and (2) is aligned with the "Digital Agenda for Spain", which defines the roadmap for Spain to meet the "Digital Agenda for Europe" from 2015 to 2020, and also for the development of the economy and the digital society in Spain (Spain, 2014c).

In the Netherlands, a report on the meaning of "Smart Industry" was presented at the Hannover Messe, in April 2014, that defines and explains the smart industry vision in the Dutch context (FME Association, 2014). After that, in November 2014, its corresponding Action Agenda was devised by the Smart Industry Team of the Dutch government in accordance with three main action lines: (1) capitalization on existing knowledge, (2) acceleration in field labs and (3) reinforcement of foundations (Netherlands, 2014).

In Italy, since September 2012, the Italian Technology Cluster "Fabbrica Intelligente" has been set up by the Italian Ministry of Education, Universities and Research (MIUR) to promote, facilitate and support: (1) research and innovation in manufacturing systems, and (2) development of the national manufacturing industry (Cluster Fabbrica Intelligente, 2015). Recently, in September 2016, the Italian Ministry of Economic Development officially announced the "Piano Nazionale Industria 4.0", which defines both strategic and complementary measures that ltaly should implement from 2017 to 2020 (1taly, 2016)

In the European Union, in December 2013, the new contractual Public-Private Partnership for the "Factories of the Future (FoF)" was publicized under the European Union Framework Programme for Research and Innovation, named "Horizon 2020", planning to provide nearly 1.15 billion euros of available funding specifically for 
FoF initiatives from 2014 to 2020 (European Factories of the Future Research Association, 2013). More recently, based upon the FoF vision, since April 2016, the preparation of a work program for 2018 to 2020, named "Factories 4.0 and Beyond", was initiated by the European Factories of the Future Research Association (EFFRA) to provide an update about how to be in synergy with the ongoing wave of "The Fourth Industrial Revolution" (European Factories of the Future Research Association, 2016).

\subsubsection{The fourth industrial revolution in Asia}

In China, the concept of "Made in China 2025" was initially proposed and recommended by the Chinese Academy of Engineering (CAE) at the beginning of 2014. Then, led by the Chinese Ministry of Industry and Information Technology (MIIT), its corresponding strategy plan was constructed. Finally, in May 2015, it was officially approved by the Chinese State Council (SC) and became a national action program alongside the "Internet+" plan. It gives priorities to ten fields in the manufacturing sector for accelerating the informatization and industrialization in China (2015).

In South Korea, "Manufacturing Innovation 3.0" was launched in June 2014 by South Korea's Ministry of Trade, Industry and Energy (MOTIE), to keep up with the changes in modern manufacturing paradigms (South Korea, 2014). It envisions to promote and realize the smartization of 10 thousand factories through the integration of IT, software, services, and new production methods, such as, 3D printing, by the year 2020.

In Japan, the concept of the fourth industrial revolution can be traced back to July 2010, in the book written by Dr. Hiroshi Fujiwara (2010). This book highlights the use of solar energy, electric cars and smart grids in a more intelligent and integrated society that bridges more seamlessly the gap between consume and production. However, until December 2015, the report on "the 5th Science and Technology Basic Plan" was finally published by the Council for Science, Technology and Innovation (CSTI) of the Japanese Cabinet Office (Council for Science Technology and Innovation, 2015), identifying actions to create new value for the development of future industry and social transformation, namely the realization of the world-leading "Super Smart Society".

In Singapore, the new Research, Innovation and Enterprise (RIE) national strategy, named RIE 2020, has been published by Singapore's National Research Foundation (NRF) to grow industry research and development capabilities, nurture innovative enterprises and meet its national needs (National Research Foundation, 2016). Advanced Manufacturing and Engineering has been listed as one of the four key technology domains, in which, eight key industry verticals and four cross-cutting technology areas are identified.

In Taiwan, a province of China, the "Taiwan Productivity 4.0 Initiative" was announced by its Executive Yuan (EY) in September 2015 as a response to the fourth industrial revolution and encompasses a wider scope (Executive Yuan, 2015). It promotes the application of "smart" technologies for the upgrade and transformation not only of traditional manufacturing industries such as metal processing, transportation equipment, $3 \mathrm{C}$ (computers, communications and consumer electronics), foods, textiles, pharmaceuticals and health, and logistics, but also for the service and agriculture industries.

In India, the initiative named "Make in India" was announced by the Indian Prime Minister in September 2014 and managed by the Department of Industrial Policy \& Promotion (DIPP) to transform India into a global design and manufacturing hub (Department of Industrial Policy and Promotion, 2014). Different from other public policies, its main focus is to foster investments and to build best-in-class manufacturing infrastructure in its 25 prioritized sectors.

In Malaysia, the "Eleventh Malaysia Plan" was released by the Economic Planning Unit (EPU) of the Prime Minister's Department in May 2015 (Economic Planning Unit, 2015), in which manufacturing is identified as one of the seven main focus areas. The main objective is the transformation of its three main manufacturing subsectors (Electrical and Electronics, Chemicals, Machinery and Equipment) towards more high-value, diverse and complex products.

\subsubsection{Comparison of the public policies}

\subsubsection{Durations}

The analysis of the start year and end year of each public policy considered the years that are explicitly covered by the corresponding plans. In case the duration is not mentioned or implicit within a plan, the year of announcement or publication was used as the start year. Table 3 illustrates the countries and regions of those plans, the continents they belong to, the start years and end years, and their durations. 


\begin{tabular}{cccc} 
Table 3. The duration of each public policy. & \\
\hline Continent & Start Year & End Year & Duration \\
\hline North America & 2011 & N/A & N/A \\
Europe & 2012 & 2020 & 9 \\
Europe & 2013 & 2020 & 8 \\
Europe & 2013 & 2050 & 38 \\
Europe & 2014 & 2020 & 7 \\
Asia & 2014 & 2020 & 7 \\
Asia & 2014 & N/A & N/A \\
Europe & 2014 & N/A & N/A \\
Europe & 2015 & 2020 & 10 \\
Asia & 2016 & 2025 & N/A \\
Europe & 2015 & N/A & 5 \\
Asia & 2016 & 2020 & 9 \\
Asia & 2016 & 2024 & 5 \\
Asia & 2016 & 2020 & 15 \\
North America & 2016 & 2030 & 15 \\
North America & 2016 & 2030 & 5 \\
Asia & 2016 & 2020 & 4 \\
Europe & 2017 & 2020 & \\
\hline & & & 5 \\
\hline
\end{tabular}

According to the start years, the first public policy related to the fourth industrial revolution was published by the United States in June 2011, and not by Germany, which is what most people think. Moreover, it can be found that, on the one hand, from 2011 to 2013, all five published public policies are from developed countries in North America and Europe. On the other hand, the public policies from the countries and regions in Asia (such as South Korea and China) began to appear in 2014.

Based on the end years, besides the four countries without an explicit end year in their public policies (the United States, India, the Netherlands, and Spain), more than half of the rest of the countries and regions $(64.3 \%)$ set the end date for their plans by 2020. It can also be found that, as one of the top ten manufacturing countries (Deloitte, 2016), the United Kingdom has already commissioned a long term and strategic look at the future of manufacturing up to the year of 2050.

Finally, from a duration perspective, among those public policies that explicitly express their start years and end years, $28.6 \%$ of them (4 plans) are four or five-year plans, $42.8 \%$ of them ( 6 plans) cover between 6 to 9 years, and $28.6 \%$ of them (4 plans) have a duration equal to or longer than 10 years.

\subsubsection{Main objectives}

The analysis of main objectives provides a summary of the main reasons for which each public policy was created, along with elements and aspects that help those countries or regions to address their own issues. To avoid a subjective conclusion, only the sentences from the plans that contain "objective" and its synonyms, such as "intention", "aim", "goal" and "purpose", were considered as candidates for this analysis. Besides those public policies without a corresponding English translation (China, Taiwan, and South Korea), which were separately analysed, 309 sentences from the remaining plans were collected. During the analysis, those sentences were further refined through examining whether, or not, they were related to the objective of the public policy. As can be seen in Table 4, according to the main reasons (the Whys) that a public policy was created, specific actions (the Hows) have been proposed to address their main concerns (the Whats).

From the perspective of the Whys, besides the Netherlands, which provides a general intention ("to become fit for the future"), the other 15 countries and 2 regions express more specific reasons. The two main reasons for the creation of public policies related to the fourth industrial revolution are (1) to improve exports and support economic growth (61.1\% - 11 countries), and (2) to increase, maintain, or regain competitiveness (55.6\% - 8 countries and 2 regions). Additionally, the objectives related to enable more sustainable production have already begun to attract attentions and is mentioned by 4 countries and 1 region (27.8\%).

From the perspective of the Whats, the main concerns are related to "Human" aspects, accounting for $61.1 \%$ (9 countries and 2 regions), from which the top two concerns are "to create high skilled and qualified jobs in manufacturing", mentioned by 5 countries and "to secure employment", mentioned by 2 countries and 2 regions. It is followed by the concerns related to "Product" and "Infrastructure" aspects, which make up 
Table 4. Summary of main objectives from the public policies.

\begin{tabular}{|c|c|c|c|c|c|c|c|c|c|c|c|c|}
\hline \multirow[b]{3}{*}{ Country/Region } & \multicolumn{12}{|c|}{ Reason } \\
\hline & \multicolumn{6}{|c|}{ How } & \multicolumn{3}{|c|}{ What } & \multicolumn{3}{|c|}{ Why } \\
\hline & 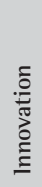 & 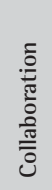 & 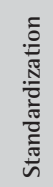 & 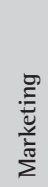 & 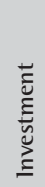 & 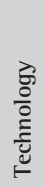 & 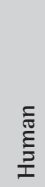 & $\begin{array}{l}\frac{\tilde{U}}{2} \\
\frac{\tilde{0}}{0} \\
\dot{0}\end{array}$ & 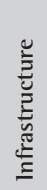 & 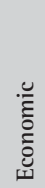 & 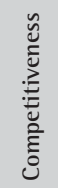 & 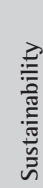 \\
\hline US & 1 & 1 & & & 1 & 1 & 1 & & 1 & 1 & 1 & \\
\hline Germany & 1 & & & 1 & & 1 & 1 & 1 & & & 1 & \\
\hline France & & & 1 & & & 1 & 1 & & & 1 & 1 & 1 \\
\hline UK & & 1 & & & & & & 1 & & 1 & 1 & 1 \\
\hline Europe & 1 & & & & 1 & 1 & 1 & 1 & 1 & & 1 & 1 \\
\hline South Korea & 1 & & & & & & & & 1 & 1 & & \\
\hline India & & & & & 1 & & & & 1 & 1 & & \\
\hline Netherlands & 1 & 1 & & & & 1 & & 1 & & & & \\
\hline Sweden & & & & & & & 1 & 1 & 1 & & 1 & 1 \\
\hline China & 1 & & & & & 1 & & 1 & 1 & 1 & 1 & \\
\hline Spain & & & & & & & 1 & & 1 & 1 & & \\
\hline Malaysia & 1 & & & & & 1 & 1 & 1 & & 1 & & \\
\hline Taiwan & 1 & & & & & 1 & 1 & & & & 1 & \\
\hline Japan & 1 & 1 & 1 & 1 & & 1 & 1 & & & 1 & & 1 \\
\hline Mexico & 1 & 1 & & & & 1 & 1 & 1 & & & 1 & \\
\hline Canada & 1 & & & & 1 & 1 & & 1 & & 1 & & \\
\hline Singapore & & & & & 1 & 1 & 1 & & & 1 & & \\
\hline 1taly & 1 & & & & & & & 1 & 1 & & 1 & \\
\hline
\end{tabular}

55.6\% (9 countries and 1 region) and 44.4\% (7 countries and 1 region), respectively. More precisely, these two aspects are mainly focusing on the "increasing productivity and resource efficiency" (7 countries and 1 region) and "modernizing (or digitalizing) industries" (6 countries and 1 region).

From the perspective of the Hows, there is a great difference between the aspects of "Innovation" and "Technology", and the aspects of "Marketing", "Standardization", "Collaboration", and "Investment". The first group is more frequently mentioned in the purposes of 10 countries and 2 regions (66.7\%). For "Innovation", "to accelerate and improve innovation capabilities" is highlighted as one of the key enablers in 7 countries. For "Technology", "to develop cutting-edge technologies" and "to adopt and apply the latest technologies" were mentioned by 8 countries and 2 regions. The second group, which encompasses "Marketing", "Standardization", "Collaboration", and "Investment", is only cited by $11.1 \%, 11.1 \%, 27.8 \%$ and $27.8 \%$ of the plans, respectively. Even so, a point to note is the proposition of "Marketing" CPS technology and products by Germany, which intends to be a supplier of Industry 4.0 equipment, research, technology and training. Other objectives mentioned in these group are, "to support standardization" (2 countries), "to collaborate among industry, academia, labour organizations, and government agencies" (5 countries), and "to provide good environment for retaining and attracting investments" (5 countries).

\subsubsection{Public funding}

The analysis of funding, in terms of governmental investments for initiatives related to the fourth industrial revolution, is based either on (1) the description of the investment amount in each country's or region's official documents, or (2) the relevant information provided by the organizations in charge of the corresponding public policies. It turns out that France, Singapore, the United States, Taiwan and Europe are the only three countries and two regions that explicitly provide the amount of funding in their reports. After the extended investigation, Germany, ltaly, Spain and the United Kingdom are being added to the previous list. More specifically:

- In France, 1.9 billion euros have been provided in public support (subsidies or repayable advances) since 2013 for new industrial projects, particularly as part of the invest for the future programme until 2016; 
- In Singapore, its government wants to sustain its commitment to research, innovation and entrepreneurship, and promises to invest 3.3 billion Singapore Dollars specially for "Advanced Manufacturing and Engineering" in its RIE2020 Plan from 2016 to 2020;

- In the United States, $\$ 2.2$ billion US Dollars were invested by the federal government in advanced manufacturing R\&D projects in 2013, nearly a $20 \%$ increase over the previous year;

- In Taiwan, since October 2015, an investment of around 36 billion Taiwan Dollars was especially planned for its "Taiwan Productivity 4.0 Initiative" until the year 2024;

- In Europe, the budget allocated within "Horizon 2020" for the "Factories of the Future" contractual Public-Private Partnerships amounts to 1.15 billion euros over the 7-year period (2014-2020);

- In Germany, until May 2017, over 550 million euros have been approved and invested for research on "Industrie 4.0". Meanwhile, an amount of 64 million euros is currently available to support medium-sized companies in the digitization, networking and introduction of Industry 4.0 applications;

- In Italy, the volume of early stage investments mobilized for its "Piano Nazionale Industria 4.0" for the 2017 to 2020 period is more than 2.6 billion euros;

- In Spain, according to their approved budget for the year of 2017, the amount of funding for the "Industria Conectada 4.0" is around 78 million euros;

- In the United Kingdom, over the past three years, Innovate UK has invested over 200 million pounds in transformative digital technologies such as additive manufacturing, robotic and autonomous systems, modelling and simulation, augmented and virtual reality, data analytics, and artificial intelligence.

Figure 3 shows the amount spent by year by each one of these 7 countries and 2 regions according to the data collected, considering the years for which information is available. All the above-mentioned countries and regions, except the United States, invested less than 1 billion Euros per year, of which six (Singapore, Germany, Europe, Taiwan, the United Kingdom and Spain) invested less than 500 million euros per year, with the other two (Italy and France) investing around 870 and 630 million Euros per year, respectively. The United States is the only country that invested around 2 billion euros per year. It is also worth noting that, even through the announcement of its fourth industrial revolution plan (2017) being later than the other European countries, Italy has already shown its ambition to create the ltaly way of "Industria 4.0" from the investment aspect.

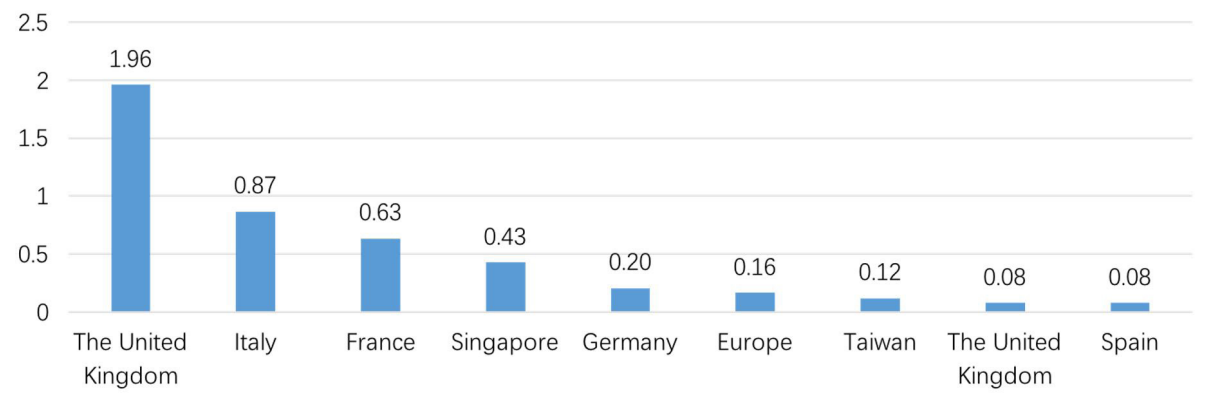

Figure 3. Annual investment in initiatives related to the fourth industrial revolution in billion euros.

\subsubsection{Areas for action}

For the analysis of the areas for action, data were collected from the contents that describe their main activities, represented by terms such as, "strategic guidelines", "pillars", "prioritized areas", "prioritized tasks", and "action agenda". In total, ten main areas were identified, as follows:

- Research and innovation: to develop cutting-edge technologies, enable interdisciplinary cooperation and create new industrial production testbeds;

- Work, education and training: to organize and design work, instruct engineering students, and prepare skilled workforces; 
- Infrastructure modernization: to support the digital transformation of small and medium enterprises (SME) and build best-in-class manufacturing infrastructure;

- Business environment: to develop policies and provide preferential policies to support organizations that either embrace or are most impacted by the fourth industrial revolution;

- Reference architecture, standards and norms: to standardize Machine-to-Machine (M2M) communication and create new infrastructure for the manufacturing sectors;

- Green manufacturing: to enable sustainable value networks and increase energy efficiency;

- Legal framework: to protect Intellectual Property (IP) and data;

- Security of networked systems: production data security and cyber security;

- Internationalization: to promote international collaboration and create national production brands;

- Industry showcasing: to promote national industrial excellence abroad.

As can be seen from Figure 4, it was found that 100\% of the studied countries and regions have actions related to "Research and Innovation". Actions related to "Work, Education and Training" and "Infrastructure Modernization" follow, amounting to 83.3\% (13 countries and 2 regions) and 55.5\% (9 countries and 1 region) respectively. These three areas not only illustrate but also confirm the priority and importance of the "Innovation", "Technology", "Human", and "Infrastructure" aspects in the analysis of main objectives (Section 3.2.2.2). Moreover, actions within the areas of "Business Environment", "Reference Architecture, Standards and Norms", "Green Manufacturing", "Legal Framework", and "Security of networked systems" were also found ranging from $16.7 \%$ to $27.8 \%$. Finally, France is the only country that carried out actions in the "Industry Showcasing" area. It aims to provide visibility for innovative French technical solutions and to share best practices among national and international innovation and business ecosystems.

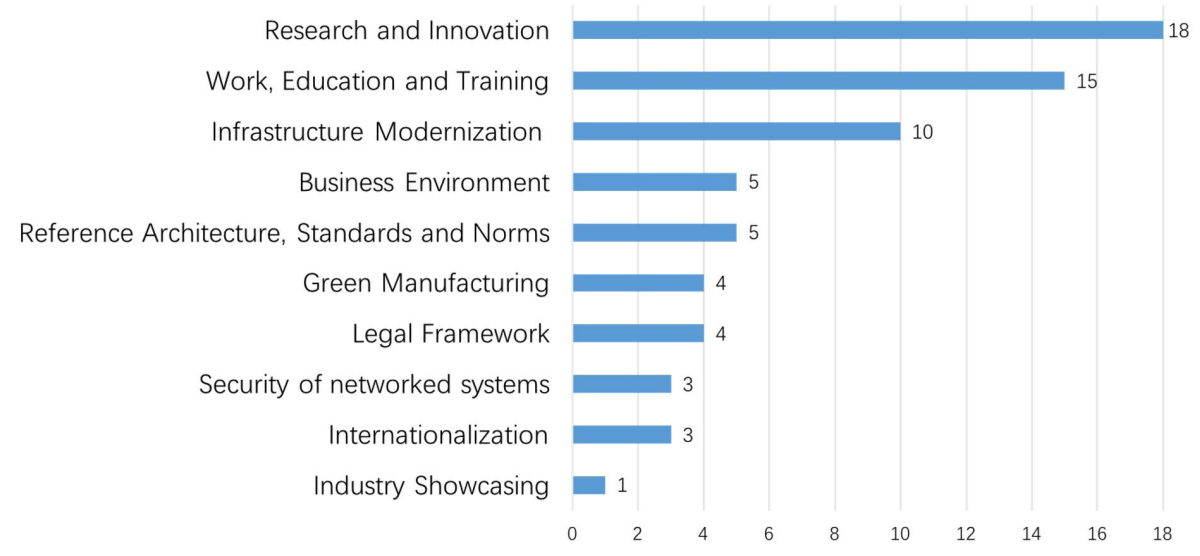

Figure 4. Number of public policies citing each main area for action.

\subsubsection{Focused manufacturing sectors}

For the focused manufacturing sectors, to avoid semantic confusions, the definition of manufacturing sectors needs to be clarified. In this paper, a manufacturing sector refers to "[...] the mechanical, physical, or chemical transformation of materials, substances, or components into new products", as defined by the North American Industry Classification System (NAICS) (Office of Management and Budget, 2017, p. 17). Moreover, as it is illustrated in Figure 5, the 21 subsectors of the manufacturing sectors defined by NAICS are employed. Results are then consolidated based on two rules: (1) manufacturing sector collection only takes into account explicit descriptions of the focused sectors in the corresponding public policies, but not simple cited expression of sector examples, and (2) data analysis only includes sectors within the manufacturing sector, excluding others. For example, "Renewable Energies" and "Thermal Renovation of Buildings" in France's plan are excluded because they are classified as a part of the Utilities and Construction sectors in NAICS. 


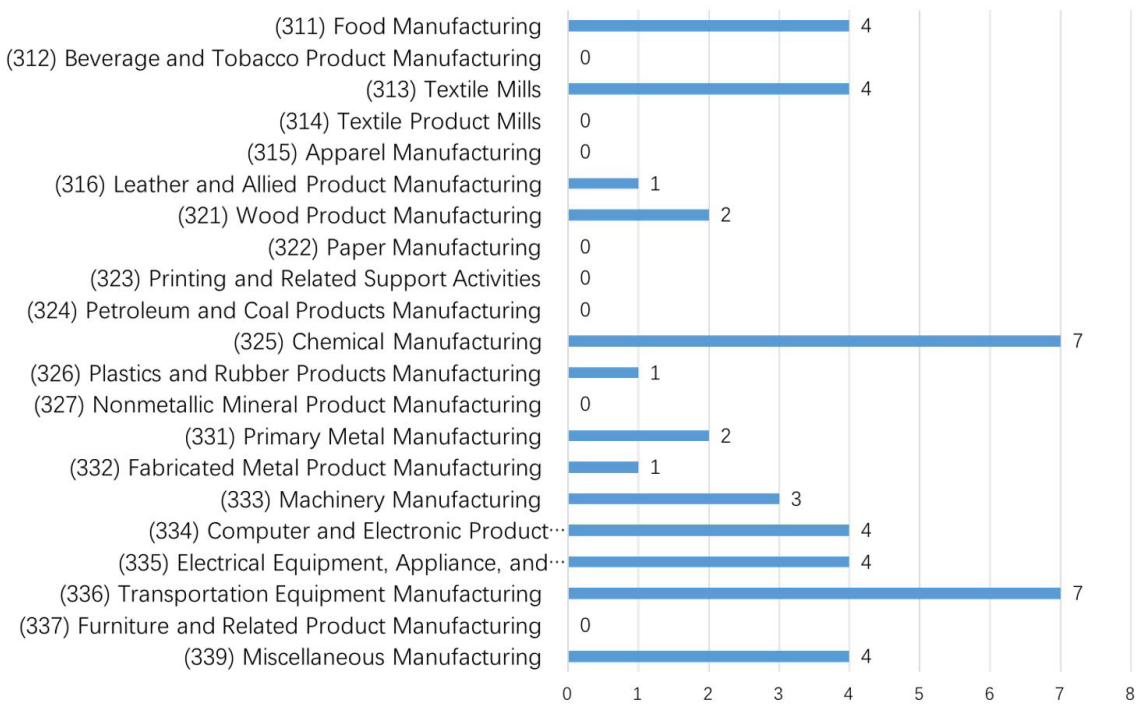

Figure 5. Focused manufacturing sectors in the public policies based on NAICS.

It can be found that, France, India, China, Malaysia, Singapore, Mexico and Taiwan are the only 6 countries and 1 region that explicitly express the focused manufacturing sectors in their public policies. As can be seen in Figure 5, all these countries and region have highlighted the (325) Chemical Manufacturing Sector and the (336) Transportation Equipment Sector. More specifically, for the former sector (325), its subsector (3254) Pharmaceutical and Medicine Manufacturing is the most valued, which is explicitly identified by France, India, China, Malaysia, Singapore and Taiwan. For the latter sector (336), its subsector (3364) Aerospace Product and Parts Manufacturing turns out to be the major trend in the fourth industrial revolution era by France, India, China, Malaysia, Singapore and Mexico.

\subsubsection{Prioritized technologies}

Industrial revolutions have always been related to the enhancement of technological capabilities in their historical periods. The search to increase efficiency and productivity makes the manufacturing sector one of the main actors during technological transformation and innovation. Nowadays, this evolution is determined by the fourth industrial revolution, so that the upgrade of technologies to meet new demands is fully integrated into today's decentralized CPS in smart factories (Saturno et al., 2017).

The current scientific literature has already shown a slight variation among the major technological enablers of the fourth industrial revolution. This change, although small, exists and should be considered, since the main goal of Q2 is to show the similarities and differences between the main public policies. For a better classification and comparison among these plans, the framework created by Saturno et al. (2017), which consolidates the technology classification of a set of consulting reports, is employed in this paper. It identifies 10 main technology categories and their particularities: advanced robotics, big data/analytics, cloud computing, cognitive computing, cybersecurity, loT, M2M, mobile technologies, radio frequency identification (RFID) technologies and additive manufacturing (3D printing).

Among the 18 collected public policies, five of them (India, Sweden, Malaysia, Singapore, and Germany) haven't explicitly stated which technologies will be given priority. For the rest, some do not present their prioritized technologies exactly as the above-mentioned categories and extra classification efforts were performed. For example, the "Artificial Intelligence" technology cited in Japan's plan is classified as part of the "(4) Cognitive Computing" in the presented framework. Figure 6 shows results of the classification. It turns out that, the "(2) Big Data/Analytics" and "(10) 3D Printing" appear to be the most popular technology categories, prioritized by 9 public policies. On the other hand, "(7) Machine-to-Machine" and "(8) Mobile Technologies" attract less attention, being only mentioned by 3 public policies. Moreover, it can also be found that France is the only country, which covers all technology categories in this framework. 


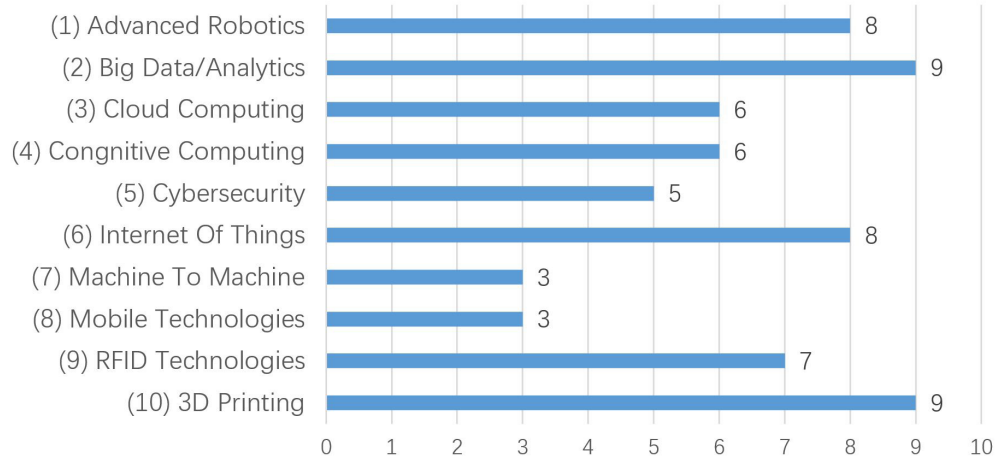

Figure 6. Prioritized technologies in public policies.

\section{Discussion}

\subsection{Definitions of the fourth industrial revolution}

It is worth noting that, among all collected papers from this systematic literature review, the concept about "The fourth industrial revolution" was firstly proposed by a paper in 1985 (Rostow, 1985), which uses the concept of the Kondratieff Cycle and long-term cyclical trends in resource enhancing activities to discuss its meaning for forestry. Then, before 2012, this concept was more frequently referred to in the development and application of nanotechnology (Dai, 2006; Hung et al., 2012; Parthasarathi \& Thilagavathi, 2011). After that, since 2012, diverse understanding about this concept still exists, e.g., (Hassan et al., 2016) equals it to the automation and machine era, and (Sumari et al., 2017) refers to it as the use of Big Data in the field of brain, mind and neurosciences. In this paper, the commonly recognized definition, namely for the fourth industrial revolution as the technical integration of CPS into manufacturing and logistics and the use of loT in industrial processes, is adopted (National Academy of Science and Engineering, 2013).

\subsection{Discussion of comparisons}

The 18 collected public policies are strategic in their nature, covering at least a 4-year span. Some are more detailed than others, but their overall goals are similar: to achieve a better alignment of initiatives related to the fourth industrial revolution and, meanwhile, to receive the most benefits. They also highlight that industrial organizations need to be better prepared to transform their production environments based on the emergence of technologies that foster integration, collaboration, flexibility, cognition and connectivity. It is a call for action from governments to organizations. Moreover, according to the analysis and comparison of these public policies, some interesting alignments are found. More precisely, three main aspects are explained as follows.

The first alignment can be found between how governments intend to address issues related to the fourth industrial revolution, namely through "Innovation" and "Technology" (Section 3.2.2.2), and the first focused area for action, namely "Research and Technology" (Section 3.2.2.4). In this sense, it is not surprising to discover that the areas related to theoretical and technological development would rank highest in these plans. That is also why the fourth industrial revolution is strongly relying on the advance of science and technology, which has already become a necessary condition for a country or region to position itself at its forefront.

The second alignment is seen between the main concern of this industrial revolution, namely the "Human" aspect (Section 3.2.2.2), and the second focused area for action, namely "Work, Education and Training" (Section 3.2.2.4). Most countries and regions have noticed the need to better qualify their workers and to improve their productivity while maintaining a balance between the employment rate and the trend of adopting more automated production technologies (that depend less on human labour). This should prompt not only industrial organizations but also educational institutions to be prepared.

Finally, the government spending to address these issues, although substantial, remains relatively low when compared to Gross Domestic Product (GDP), amounting for less than 0.05\% of the GDP of the studied countries and regions. For countries such as Germany and France, that implicitly state in their plans objective of positioning themselves as providers of solutions for the fourth industrial revolution, investments of $0.005 \%$ and $0.025 \%$ of their GDPs, respectively, might have to be increased in the next years. 
Therefore, one might conclude, from this analysis that the studied countries and regions have already focused on the technology and innovation to improve their overall competitiveness. Meanwhile, an emphasis on sustainability aspects through better products, workforce qualification and infrastructure has also appeared. That is, meeting the demands of a more integrated and sustainable society through the application of technology.

\subsection{The forth industrial revolution in Brazil}

In Brazil, the digital transformation of manufacturing industries is characterized by the integration of sensors and networked equipment into production and control, which makes the fusion of the real with the virtual worlds possible (Confederação Nacional da Industria, 2016). According to this report (Confederação Nacional da Industria, 2016), there are still few companies that are fully prepared to embrace this concept, although there are many that must gradually participate in its diffusion, according to their strategies. Combining government incentives with the experience of organizations that have already pioneered some aspects of this new paradigm will result in a stimulus for others, at the risk of not being able to survive in a new competitive environment.

It is possible to tacitly express the impacts that the advancement of the Brazilian economy's digitalization may have on the country's competitiveness. The strategic consulting firm, Accenture, estimates that the implementation of loT technologies in various sectors of the economy should increase Brazilian GDP by approximately 39 Billion Dollars by 2030 (Confederação Nacional da Industria, 2016). Therefore, if Brazil creates conditions to improve the business environment, such as programs of technological diffusion and regulatory improvement, the gain can surpass 210 Billion Dollars. The reflection of the fourth industrial revolution is not restricted only to numerical values, but also encompasses the impact of its dissemination and consolidation, which also requires a reformulation of industrial policy at the national level.

Despite these expressive numbers, one of the necessary conditions related to the fourth industrial revolution, there are just a few national industries that understand the concept of digital technologies and their incorporation. More specifically, more than $42 \%$ of Brazilian companies are unaware of its importance (Confederação Nacional da Industria, 2016). Moreover, only 9\% of Brazilian companies are classified as advanced in digitalization. But the report is betting on an accelerated advance in this area in the coming years. By 2020, the expectation is that the percentage will jump to $72 \%$. On the other hand, a good perspective on the development of the digital industry in Brazil is the attractiveness of the domestic industry to the domestic market. The fourth industrial revolution presents opportunities for developers and suppliers of solutions to a new technological environment.

\subsection{Implications for the public sector: industrial policy development}

In the current public policy literature, there already exist several authors that discuss the policy development process, particularly for improving manufacturing industries, as well as for economic development (Milberg et al., 2014; Felipe, 2015; Lazzarini, 2015). On the one hand, some of them argue that government plays a role in governing strategic paths that manufacturing industries in a given country should choose. On the other hand, those works still have no intersections with the fourth industrial revolution.

Therefore, by analysing the public policies from different countries and regions, some implications for industrial policy development, which encompass the efforts of the fourth industrial revolution, can be drawn. A set of recommendations according to the findings of this paper are presented. Following the ten design principles for industrial policy that were developed by Rodrik (2004), the recommendations are discussed next:

- "Incentives should be provided only to 'new' activities": the analysed plans foresee support for activities related to the technologies that a country does not possess. This is usually a result of a diagnosis that is performed through a series of meetings involving experts from both industry and academia. Hence, the first step in the industrial policy development is a comprehensive diagnosis of industries' existing capabilities in a given country. It can determine which activities need more investment for obtaining new capabilities;

- "There should be clear benchmarks/criteria for success and failure": this is one of the principles that is lacking in the analysed plans. Criteria for success are usually defined in general terms, such as in the technologies that a country's industry should master. The recommendation here is to be more explicit in how one would determine that a given technology is mastered by defining unambiguous indicators or performance measures, such as the percentage of products that incorporate a given technology;

- "There must be a built-in sunset clause": 14 out of 18 analysed plans determine a sunset clause in the form of a duration, after which it would be evaluated and new objectives and actions would be defined. Typically, this must 
be done in connection with the definition of criteria for success (as discussed in the previous principle), that measure the progress in the achievement of the plan and may help determine when the plan is no longer needed. Hence, a review process for an industrial policy and its success criteria has to be determined, including its periodicity;

- "Public support must target activities, not sectors": the analysed plans target a hybrid of activities and sectors, as can be seen in Figure 4 of Section 3.2.2.4 and Figure 5 of Section 3.2.2.5. Activities are targeted in sectors that demonstrate potential for a "quick win", i.e., for which a given country already has an installed infrastructure and possesses capabilities to meet demands. Although not purely focusing on activities, it is believed that this is a decision made through a trade-off analysis, by promoting sectors in which it is thought that the chosen activities will have the most impact. Hence, it is recommended that sectors that would be targeted be chosen based on the impact of the necessary activities;

- "Activities that are subsidized must have the clear potential of providing spillovers and demonstration effects": the three most predominant areas for action from Section 3.2.2.4 have a clear potential to provide longer term benefits. Research and Innovation will increase the overall competitiveness of a country in the development of products and processes that are more aligned to customers' demands. Work, Education and Training will not only increase productivity but also enable a better work-life balance. Infrastructure Modernization is the baseline of the fourth industrial revolution, through which a country will have more opportunities in the global marketplace. Hence, for an industrial policy about the fourth industrial revolution, these three areas for action are the main topics to be considered;

- "The authority for carrying out industrial policies must be vested in agencies with demonstrated competence": this is the case for all analysed plans - they were prepared by the major governing bodies for industry and development in their respective countries and regions, and also with the participation of major stakeholders;

- "The implementing agencies must be monitored closely by a principal with a clear stake in the outcomes and who has political authority at the highest level': this principle is probably the most difficult to be analysed and put into practice. It is expected, if plans are made by the governing bodies with authority and competence to do so, that they will be carried out. Nevertheless, political commitment in putting the plans in action must be presented. As the fourth industrial revolution is a hot topic in the moment, political support is not difficult to obtain. In fact, as industry demands public funding and investment, as seen in Section 3.2.2.3, the current investment is substantial;

- "The agencies carrying out promotion must maintain channels of communication with the private sector": as it is only explicitly highlighted by 5 out of 18 analysed plans, Collaboration still doesn't receive sufficient attention (see Table 4 of Section 3.2.2.2). This principle promotes a direct connection between the governing bodies and industries in the private sector, mainly because it is a consequence of focusing on research, innovation, training, education and infrastructure. Therefore, this existing issue is recommended to be resolved in the near future;

- "Optimally, mistakes that result in 'picking the losers' will occur": this principle is related to the second and third principles. It is recommended to accept errors, study them and review and adjust industrial policies to incorporate lessons learned;

- "Promotion activities need to have the capacity to renew themselves, so that the cycle of discovery becomes an ongoing one": though the analysed plans haven't explicitly emphasized this point, the concept can be found from their main objectives. As can be seen from Table 4 of Section 3.2.2.2, most of the plans put Innovation and Technology (How), Human (What) and Economic (Why) aspects as their predominant features. To be more specific, the focus on the Human aspect has the potential to accelerate the development of Innovation and Technology, which, in turn, will generate Economic growth that might be directed to more investment in Human aspects. Therefore, it is recommended to use these four aspects as the foundation to define the goal of an industrial policy.

It must be stressed, however, that these implications for industrial policy development need to be considered with care. Even though they aim to be comprehensive regarding the content of any policy towards the fourth industrial revolution, they still need to be further adjusted and validated according to the requirements of different situations.

\subsection{Implications for the academic community}

In a recent paper published in the International Journal of Production Research (1JPR), Liao et al. (2017) conducted a systematic literature review of "Industrie 4.0" and came to several conclusions regarding how "Industrie 4.0" has been addressed by the academic community. One of them is the distribution of research efforts according to priority areas for action, based on 123 papers, as can be seen in Figure 7. 


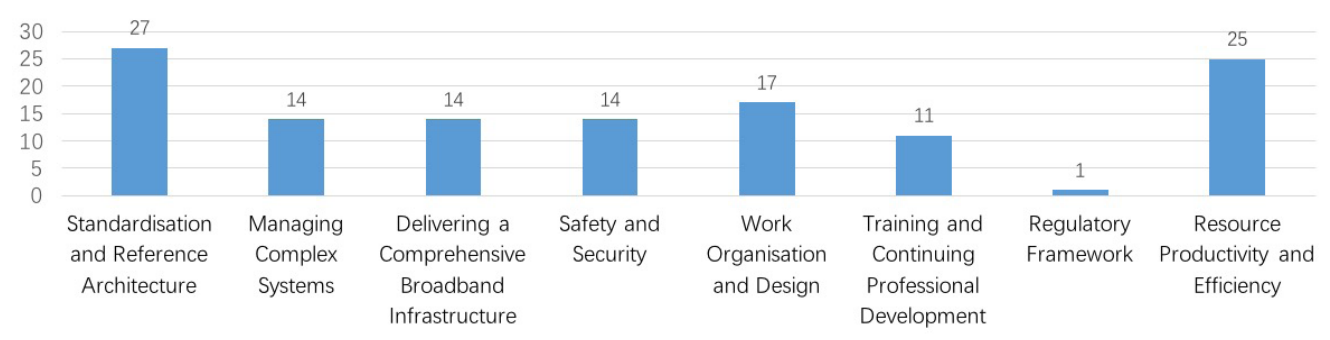

Figure 7. Distribution of academic papers according to priority areas (Liao et al., 2017).

It can be stated that the academic community of "Industrie 4.0" has been focusing on two main areas: "Standardization and Reference Architectures" and "Resource Productivity and Efficiency". Comparing to the three main areas for action listed in Figure 4 of Section 3.2.2.4, some implications can be drawn.

On the one hand, there are some similarities:

- "Research and Innovation" is not directly presented in Figure 7. But it can be considered as the fundamental driver of all the eight Priority Areas for action in "Industrie 4.0". For example, through "Research and Innovation" in manufacturing processes, one of the forthcoming and obvious results is the improvement in "Resource Productivity and Efficiency";

- "Work, Education and Training" can cover at least two main Priority Areas for action in "Industrie 4.0", namely "Work Organization and Design" and "Training and Continuing Professional Development". The sum of these two areas (28 papers) will rank first in the number of papers when compared to the other six areas in Figure 7;

- "Infrastructure Modernization" is directly related to the Priority Area of "Management of Complex Systems" and "Delivering a Comprehensive Broadband Infrastructure". It is the same as the previous one, the sum of these two areas (28 papers) will also rank first.

On the other hand, some differences were also found. Comparing the Priority Areas "Standardization and Reference Architectures" and "Safety and Security" in "Industrie 4.0" in Figure 7, their corresponding Areas for Action "Reference Architecture, Standards and Norms" and "Security of Networked Systems" are only taken into account by 5 out of 18 and 3 out of 18 of the analysed public policies, respectively.

To sum up, academic communities are recommended to direct their efforts to the three main focus areas mentioned by most of the public policies (namely "Research and Innovation and Work", "Education and Training", and "Infrastructure Modernization"), to promote a better alignment between academic communities, industries and governing bodies, and to be able to obtain more support from a given country or region.

\section{Conclusion}

The main objective of this research is to provide a global panorama of the most relevant public policies in the emerging fourth industrial revolution by analysing their similarities and differences. A mixed systematic literature review method is applied to conduct such analysis, in which, a sample of 67 papers and 18 government plans were first qualitatively and then quantitatively analysed. More precisely, the comparison of these public policies' durations, objectives, available funding, areas for action, focused manufacturing sectors, and prioritized technologies was performed.

In general terms, all the studied public policies either mention or are based on the German public policy "Industrie 4.0". Regarding the durations of these plans, a higher percentage (42.8\%) of them are set in between 6 and 9 years. Concerning their objectives, to support economic growth $(61.1 \%)$ and to increase, maintain or regain competitiveness (55.6\%) are the main reasons for the creation of public policies. To achieve those targets, specific activities, mainly related to Innovation and Technology (66.7\%), are carried out and applied on three objects: Human (61.1\%), Product (55.6\%), and Infrastructure (44.4\%). In terms of investments, the United States, Italy, and France are at the top. Three main areas for action in this new industrial revolution were also identified, namely "Research and Innovation", "Work, Education, and Training", and "Infrastructure Modernization". In addition, more attention is given to two manufacturing sectors, to be more specific, Chemical Manufacturing and Transportation Equipment Manufacturing. Finally, from the technological aspect, a higher prioritization of Big Data/Analytics, 3D Printing, Advanced Robotics, and loT technologies can also be observed. 
There is, however, one aspect that deserves attention but is still missing in the analysed public policies. Even though much attention has been given to the research, technology, innovation and workforce qualification, less attention has been put on the development of a production management system or philosophy that is able to cope with these demands. This should be expected as the next step in this new industrial revolution, as technologies become more affordable and are mastered by most organizations.

In summary, balancing the needs for more specialized workforce, advanced technologies, more productivity, closer integration with customers, higher product quality and shorter time-to-market of products is not simple. There is a latent need for advancing managerial practices related to these elements.

\section{References}

Atzori, L., lera, A., \& Morabito, G. (2010). The internet of things: a survey. Computer Networks, 54(15), 2787-2805. http://dx.doi. org/10.1016/j.comnet.2010.05.010.

Belvedere, V., Grando, A., \& Bielli, P. (2013). A quantitative investigation of the role of information and communication technologies in the implementation of a product-service system. International Journal of Production Research, 51(2), 410-426. http://dx.doi.or g/10.1080/00207543.2011.648278.

Cambridge Dictionary. (2017). The industrial revolution. . Retrieved in 2017, December 5, from https://dictionary.cambridge.org/ dictionary/english/industrial-revolution

Canadian Manufacturers \& Exporters - CME. (2016). Industrie 2030 action plan: manufacturing growth, innovation and prosperity for Canada: report. Ottawa: Canadian Manufacturers \& Exporters.

China. State Council - SC. (2015). Made in China 2025: report. Beijing: State Council.

Cluster Fabbrica Intelligente - CFl. (2015). Roadmap per la ricerca e l'innovazione: research and innovation roadmap: report. Bologna: National Intelligent Factories Cluster.

Confederação Nacional da Industria - CNI. (2016). Desafios para indústria 4.0 no Brasil: report. Brasília: CNI.

Conseil National de L'industrie - CNI. (2013). The new face of industry in France: report. Paris: CNI.

Council for Science Technology and Innovation - CST1. (2015). Report on the 5th science and technology basic plan. Tokyo: Cabinet Office.

Dai, L. (2006). From conventional technology to carbon nanotechnology: The fourth industrial revolution and the discoveries of C60, carbon nanotube and nanodiamond. In L. Dai (Ed.), Carbon nanotechnology (pp. 3-11). Philadelphia: Elsevier.

Deloitte. (2016). Global manufacturing competitiveness index: report. London: Deloitte Touche Tohmatsu Limited.

Department of Industrial Policy and Promotion - DIPP. (2014). Make in India. India: DIPP. Retrieved in 2017, July 31, from http:// www.makeinindia.com/

Drath, R., \& Horch, A. (2014). Industrie 4.0: hit or hype? IEEE Industrial Electronics Magazine, 8(2), 56-58. http://dx.doi.org/10.1109/ MIE.2014.2312079.

Economic Planning Unit - EPU. (2015). Eleventh Malaysia plan (2016-2020): report. Kuala Lumpur: EPU.

European Factories of the Future Research Association - EFFRA. (2013). Factories of the future: multi-annual roadmap for the contractual PPP under Horizon2020: report. Brussels: EFFRA.

European Factories of the Future Research Association - EFFRA. (2016). Factories 4.0 and beyond. report. Brussels: EFFRA.

Executive Yuan - EY. (2015). Taiwan productivity 4.0 initiative: report. Taipei: Executive Yuan.

Felipe, J. (2015). Development and modern industrial policy in practice: issues and country experiences. Cheltenham: Edward Elgar Publishing.

FME Association. (2014). Smart industry: dutch industry fit for the future: report. The Hague: Ministry of Economic Affairs.

Foresight. (2013). The future of manufacturing: a new era of opportunity and challenge for the UK: report. London: Government Office for Science.

Fujiwara, H. (2010). 第4の産業革命 [The fourth industrial revolution]. Tokyo: Asahi Shimbun Publications.

Hassan, M. G., Nordin, N., \& Ashari, H. (2016). Environmental stewardship issue among Malaysian manufacturing firms. International Journal of Supply Chain Management, 5(2), 36-42.

Hung, S. W., Wang, A. P., \& Chang, C. C. (2012). Exploring the evolution of nano technology. In Proceedings of Portland International Center for Management of Engineering and Technology: Technology Management for Emerging Technologies (pp. 2598-2604). New York: IEEE.

Innovate UK. (2016). Delivery plan: financial year 2016/17: report. London: Innovate UK.

Italy. Ministry of Economic Development - MISE. (2016). Piano nazionale industria 4.0 [National industry 4.0 plan]. Rome: Ministry of Economic Development. Report.

Khaitan, S. K., \& McCalley, J. D. (2015). Design techniques and applications of cyberphysical systems: a survey. IEEE Systems Journal, 9(2), 350-365. http://dx.doi.org/10.1109/JSYST.2014.2322503.

Lazzarini, S. G. (2015). Strategizing by the government: can industrial policy create firm-level competitive advantage? Strategic Management Journal, 36(1), 97-112. http://dx.doi.org/10.1002/smj.2204.

Liao, Y., Deschamps, F., Loures, E. F. R., \& Ramos, L. F. P. (2017). Past, present and future of industry 4.0: a systematic literature review and research agenda proposal. International Journal of Production Research, 55(12), 3609-3629. http://dx.doi.org/10.108 0/00207543.2017.1308576.

Maynard, A. D. (2015). Navigating the fourth industrial revolution. Nature Nanotechnology, 10(12), 1005-1006. PMid:26632281. http:// dx.doi.org/10.1038/nnano.2015.286. 
Mexico. Ministry of Economy - SE. (2016). Crafting the future: a roadmap for industry 4.0 in Mexico: report. Mexico City: Ministry of Economy.

Milberg, W., Jiagn, X., \& Gereffi, G. (2014). Industrial policy in the era of vertically specialized industrialization. In J.M. Salazar-Xirinachs, 1. Nübler \& R. Kozul-Wright (Eds.), Transforming economis: making industrial policy work for growth, jobs and development (pp. 151-178). Genève: International Labour Organization.

Moher, D., Liberati, A., Tetzlaff, J., \& Altman, D. G. (2009). Preferred reporting items for systematic reviews and meta-analyses: the PRISMA statement. PLoS Medicine, 6(7), 264-269. PMid:19621072. http://dx.doi.org/10.1371/journal.pmed.1000097.

National Academy of Science and Engineering - ACATECH. (2013). Recommendations for implementing the strategic initiative industrie 4.0. final report of the industrie 4.0 working group. Frankfurt: ACATECH. Report.

National Research Foundation - NRF. (2016). Research, Innovation and Enterprise (RIE) 2015 plan. Singapore: Prime Minister's Office, NRF. Report.

Netherlands. Ministry of Economic Affairs - MEA. (2014). Action agenda smart industry: report. The Hague: Ministry of Economic Affairs.

Nightingale, A. (2009). A guide to systematic literature reviews. Surgery (Oxford), 27(9), 381-384. http://dx.doi.org/10.1016/j. mpsur.2009.07.005.

Nouvelle France Industrielle - NFl. (2016). New Industrial France: building France 's industrial future: report. Paris: NFl.

Office of Management and Budget - OMB. (2017). North American industry classification system: report. Washington: Office of Management and Budget.

Parthasarathi, V., \& Thilagavathi, G. (2011). Synthesis and characterization of Zinc oxide nanopartilce and its application on fabrics for microbe resistant defence clothing. International Journal of Pharmacy and Pharmaceutical Sciences, 3(4), 392-398.

Pickering, C., \& Byrne, J. (2014). The benefits of publishing systematic quantitative literature reviews for PhD candidates and other earlycareer researchers. Higher Education Research \& Development, 33(3), 534-548. http://dx.doi.org/10.1080/07294360.2013.841651.

President's Council of Advisors on Science and Technology - PCAST. (2011). Report to the president on ensuring american leadership in advanced manufacturing. Washington: Executive Office of PCAST. Report.

President's Council of Advisors on Science and Technology - PCAST. (2014). Report to the president accelerating U.S. advanced manufacturing. Washington: Executive Office of PCAST.

Rodrik, D. (2004). Industrial policy for the twenty-first century (CEPR Discussion, No. 4767). London: Centre for Economic Policy Research. Retrieved in 2017, July 31, from https://ssrn.com/abstract=666808

Rostow, W. W. (1985). The fifth Kondratieff upswing and the fourth industrial revolution: their meaning for forestry. In R.A. Sedjo (Ed.), Investments in forestry (pp. 11-19). Bowker: Westview.

Saturno, M., Pertel, V. M., Deschamps, F., \& Loures, E. de F. R., (2017). Proposal of an automation solutions architecture for industry 4.0. In Proceedings of the 24th International Conference on Production Research. Poznan: ICPR.

Siemieniuch, C. E., Sinclair, M. A., \& Henshaw, M. J. C. (2015). Global drivers, sustainable manufacturing and systems ergonomics. Applied Ergonomics, 51, 104-119. PMid:26154210. http://dx.doi.org/10.1016/j.apergo.2015.04.018.

South Korea. Ministry of Trade Industry and Energy - MOTIE. (2014). Manufacturing innovation 3.0 strategy for the creation of economy. Sejong City: MOTIE. Report.

Spain. Ministry of Industry Energy and Tourism - MINETUR. (2014a). Agenda para el fortalecimiento del sector industrial en España [Agenda for the strengthening of the industrial sector in Spain]. Madrid: MINETUR. Report.

Spain. Ministry of Industry Energy and Tourism - MINETUR. (2014b). Industria conectada 4.0: la transformación digital de la industria española [Connected Industry 4.0: the digital transformation of the spanish industry]. Madrid: MINETUR. Report.

Spain. Ministry of Industry Energy and Tourism - MINETUR. (2014c). Planes específicos de la Agenda Digital para España [Specific plans of the Digital Agenda for Spain]. Madrid: Ministry of Industry Energy and Tourism. Report.

Sumari, P., ldris, Z., \& Abdullah, J. M.. (2017). We must invest in applied knowledge of computational neurosciences and neuroinformatics as an important future in Malaysia: the Malaysian brain mapping project. The Malaysian Journal of Medical Sciences, 24(1), 1-9. PMid:28381924. http://dx.doi.org/10.21315/mjms2017.24.1.1.

Sweden. Ministry of Enterprise and Innovation - MEl. (2016). Smart industry: a strategy for new industrialisation for Sweden: report. Stockholm: Ministry of Enterprise and Innovation.

Teknikföretagen. (2013). Made in Sweden 2030: strategic agenda for innovation in production: report. Stockholm: Teknikföretagen. 